\title{
A CLINICAL STUDY ON THYROID DYSFUNCTIONS IN PREGNANCY AND ITS EFFECT ON MATERNAL AND NEONATAL OUTCOME
}

\author{
Renu Gupta1, Shaily Agarwal2, Kiran Pandey33, Neena Gupta4, Uruj Jahan ${ }^{5}$, Yashwant Kumar Rao6, Pundrik Kumar Gupta ${ }^{7}$ \\ ${ }_{1}^{1}$ Associate Professor, Department of Obstetrics and Gynaecology, GSVM Medical College, Kanpur, Uttar Pradesh. \\ ${ }^{2}$ Assistant Professor, Department of Obstetrics and Gynaecology, GSVM Medical College, Kanpur, Uttar Pradesh. \\ 3 Professor and HOD, Department of Obstetrics and Gynaecology, GSVM Medical College, Kanpur, Uttar Pradesh. \\ 4 Professor, Department of Obstetrics and Gynaecology, GSVM Medical College, Kanpur, Uttar Pradesh. \\ ${ }_{5}^{5}$ Lecturer, Department of Obstetrics and Gynaecology, GSVM Medical College, Kanpur, Uttar Pradesh. \\ ${ }^{6}$ Associate Professor and HOD, Department of Paediatrics, GSVM Medical College, Kanpur, Uttar Pradesh. \\ 7Junior Resident, Department of Obstetrics and Gynaecology, GSVM Medical College, Kanpur, Uttar Pradesh.
}

\section{BACKGROUND}

ABSTRACT

Thyroid dysfunction in pregnancy is a common occurrence. Thyroid dysfunction in pregnancy has adverse effects on maternal and neonatal outcome. So, pregnancy is seen as a risk factor in the occurrence of thyroid dysfunctions. The purpose of this study was to estimate the prevalence of different thyroid dysfunctions in pregnancy and to study their effects on foetomaternal outcome.

\section{MATERIALS AND METHODS}

This was a prospective, observational study conducted in the Department of Obstetrics and Gynaecology, GSVM Medical College, Kanpur, UP, India, over a period of 2 years (Oct. 2015 - Oct. 2017) in 1268 pregnant women attending the OPD and IPD of our hospital. The first line screening test used for diagnosis of thyroid dysfunction was serum TSH level by CLIA method.

\section{RESULTS}

The study was conducted in 1268 pregnant women. They were screened for thyroid dysfunctions by measuring serum TSH level. Thyroid dysfunction was found in 196 pregnant women (prevalence 15.5\%), out of which 11.2\% patients have subclinical hypothyroidism, 3.5\% patients have overt hypothyroidism and $0.8 \%$ patients have hyperthyroidism. Maternal complications included preeclampsia (15.8\%), abortions (12.2\%), abruptio placentae (7.14\%), PPH (4.6\%), PPROM (7.14\%) and anaemia (22.4\%). Neonatal complications included preterm birth (11.2\%), low birth weight (10.2\%), IUGR (7.14\%), still birth and IUD (6.6\%), NICU admissions (13.7\%) and low APGAR score (13.2\%).

\section{CONCLUSION}

Thyroid dysfunctions in pregnancy are increasing and adversely affect maternal and neonatal outcome, therefore all antenatal women should be screened for thyroid dysfunctions so as to minimise the adverse outcomes.

\section{KEYWORDS}

Pregnancy, Thyroid Dysfunction, Serum TSH, Maternal Complication, Neonatal Complication.

HOW TO CITE THIS ARTICLE: Gupta R, Agarwal S, Pandey K, et al. A clinical study on thyroid dysfunctions in pregnancy and its effect on maternal and neonatal outcome. J. Evolution Med. Dent. Sci. 2018;7(12):1520-1523, DOI: 10.14260/jemds/2018/344

\section{BACKGROUND}

Thyroid dysfunction is a common occurrence in pregnancy and the second most common cause of endocrine dysfunction in the pregnancy after diabetes. Thyroid dysfunctions in pregnancy may be overlooked and underdiagnosed, because of very non-specific and the physiological hypermetabolic state of normal pregnancy.

The most common thyroid dysfunction in pregnancy is hypothyroidism with an estimated prevalence of $2 \%-3 \%$ and $0.3 \%-0.5 \%$ for subclinical and overt hypothyroidism respectively.[1] Endemic iodine deficiency accounts for most cases of hypothyroidism in pregnant women worldwide while chronic

'Financial or Other Competing Interest': None.

Submission 06-02-2018, Peer Review 04-03-2018,

Acceptance 10-03-2018, Published 19-03-2018.

Corresponding Author:

Dr. Pundrik Kumar Gupta,

Room No. 7, NRH, LLR Hospital Campus,

GSVM Medical College, Kanpur-208002,

Uttar Pradesh.

E-mail: pundrikgupta@rediffmail.com

DOI: $10.14260 /$ jemds $/ 2018 / 344$

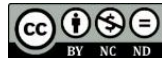

autoimmune thyroiditis (Hashimoto's thyroiditis) is the most common cause of hypothyroidism in iodine sufficient part of the world.[2]

Pregnancy is seen as a risk factor in the occurrence of thyroid dysfunction. Maternal euthyroid status is critical for healthy maternal and foetal health development. Thyroid dysfunction has varied impact on pregnancy outcome. Hypothyroidism is associated with an increased risk of obstetrical complication including preterm labour, abortions, intrauterine foetal demise and still birth, gestational hypertension, placental abruption, PPH, PPROM, anaemia and a poor perinatal outcome including preterm, LBW, IUGR, NICU admission and low APGAR score. [3]

The most notable change is the increase in thyroxinebinding globulin (TBG). This begins early in the first trimester, plateaus during mid-gestation and persists until shortly after delivery. This is due to stimulation of TBG synthesis by elevated maternal oestrogen levels and more importantly due to a reduced hepatic clearance of TBG because of oestrogen-induced sialylation. The second most important change is increased urinary iodine excretion and deiodinase type 3 activity of placenta, thus pregnancy is a state of increased thyroid hormone metabolism. HCG has 
intrinsic thyrotropic activity, which increases after fertilisation and peaks at 10 - 12 weeks. Hence, in the first trimester FT3 and FT4 levels increase slightly and TSH levels decrease in the first trimester with a readjustment in the second and third trimesters when HCG levels decrease or increase, as a consequence cut-offs to determine hypothyroidism in pregnancy are different in the first trimester and rest of the pregnancy.

The present study was conducted to know the prevalence of thyroid dysfunction in Indian pregnant women and to know their obstetrical and neonatal outcome.

\section{Aims and Objectives}

To evaluate the prevalence of thyroid dysfunction in pregnancy and its effect on maternal and neonatal outcome.

\section{MATERIALS AND METHODS}

This prospective observational study was conducted in Upper India Sugar Exchange Maternity Hospital (UISEMH), Department of Obstetrics and Gynaecology, GSVM Medical College, Kanpur for a duration of two years. 1268 antenatal women attending the outpatient and inpatient department were screened for thyroid dysfunction by measuring serum TSH level after taking informed consent and explaining the benefits of the study and after excluding patients having gestational trophoblastic disease, previous bad obstetric history with known cause, any medical co-morbidities like diabetes and hypertension, chronic medical disorders and multiple pregnancy.

The first line screening test used to assess thyroid status in patients is measurement of the serum TSH level by third generation chemiluminescent immunometric assay (CLIA), assuming normal hypothalamic-pituitary function. Serum TSH is the most reliable indicator of thyroid status, because it indirectly reflects thyroid hormone levels as sensed by the pituitary gland. Serum TSH is the gold standard marker for thyroid dysfunction and free T4 is done when serum TSH levels are found to be deranged because of economic constraints. Following trimester specific reference ranges are recommended by the American Thyroid Association 2011.[4]

\begin{tabular}{|c|c|}
\hline Trimester & S. TSH Range \\
\hline First & $0.1-2.5 \mathrm{mIU} / \mathrm{L}$ \\
\hline Second & $0.2-3.0 \mathrm{mIU} / \mathrm{L}$ \\
\hline Third & $0.3-3.0 \mathrm{mIU} / \mathrm{L}$ \\
\hline
\end{tabular}

In this prospective observational study, a total of 1268 patients were enrolled and screened for thyroid dysfunction with the aim to estimate prevalence of thyroid dysfunction and its maternal and foetal outcome. 1268 patients after screening were divided in four groups. Group 1 includes patients with normal serum TSH and normal FT4 (n- 1072), Group 2 includes patients with subclinical hypothyroidism (n- 142), Group 3 includes patients with overt hypothyroidism (n- 44), Group 4 includes patients with hyperthyroidism (n-10).

\section{RESULTS}

Prevalence of thyroid dysfunction was $15.5 \%$ in pregnant women, out of which $11.2 \%$ have subclinical hypothyroidism, $3.5 \%$ have overt hypothyroidism and $0.8 \%$ have hyperthyroidism (as shown in Figure 1 and Table 1).

\begin{tabular}{|c|c|c|}
\hline Group & $\begin{array}{c}\text { Number } \\
\text { (n) }\end{array}$ & $\begin{array}{c}\% \\
\text { Prevalence } \\
\end{array}$ \\
\hline Group 1 - Normal & 1072 & $84.5 \%$ \\
\hline $\begin{array}{c}\text { Group } 2 \text { - Subclinical } \\
\text { hypothyroidism }\end{array}$ & 142 & $11.2 \%$ \\
\hline Group 3 - Overt hypothyroidism & 44 & $3.5 \%$ \\
\hline Group 4 - Hyperthyroidism & 10 & $0.8 \%$ \\
\hline Total & 1268 & $100 \%$ \\
\hline \multicolumn{3}{|c|}{ Table 1. Prevalence of Thyroid Disorders } \\
\hline
\end{tabular}

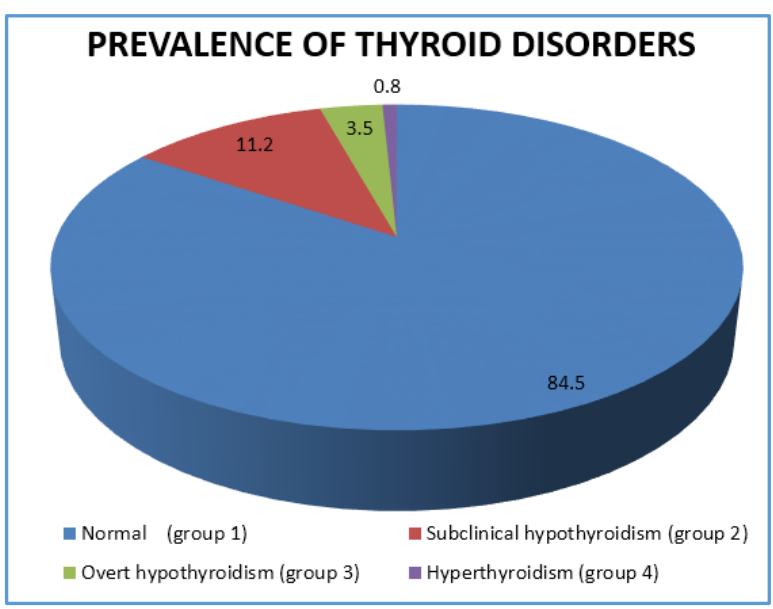

Figure 1

Mean age of women in subclinical hypothyroidism group was 25.25 years, in overt hypothyroidism group was 25.6 years and in hyperthyroidism group was 26.2 years. Mean gestational age in subclinical hypothyroidism group was 14.96 weeks, in overt hypothyroidism group was 16.18 weeks and in hyperthyroidism group was 15.8 weeks. Mean serum TSH level in subclinical hypothyroidism group was 4.86, in overt hypothyroidism group was 5.52 and in hyperthyroidism group was 0.28 (as shown in Figure 2 and Table 2).

\begin{tabular}{|c|c|c|c|c|c|c|}
\hline $\begin{array}{c}\text { Demographic } \\
\text { Profile }\end{array}$ & $\begin{array}{c}\text { Subclinical } \\
\text { Hypothyroidism } \\
\text { (Group 2) n=142 }\end{array}$ & \multicolumn{2}{c|}{$\begin{array}{c}\text { Overt } \\
\text { Hypothyroidism } \\
\text { (Group 3) n=44 }\end{array}$} & $\begin{array}{c}\text { Hyper- } \\
\text { thyroidism } \\
\text { (Group 4) } \\
\text { n=10 }\end{array}$ \\
\hline & Mean & SD & Mean & SD & Mean & SD \\
\hline Age (years) & 25.25 & 4.15 & 25.6 & 4.19 & 2.62 & 4.21 \\
\hline $\begin{array}{c}\text { Gestational } \\
\text { Age (weeks) }\end{array}$ & 14.96 & 6.29 & 16.18 & 8.47 & 15.8 & 8.54 \\
\hline $\begin{array}{c}\text { S. TSH } \\
\text { (mIU/L) }\end{array}$ & 4.86 & 4.86 & 5.52 & 1.38 & 0.28 & 0.33 \\
\hline Table 2. Demographic Profile in Different Thyroid \\
Disorders \\
\hline
\end{tabular}

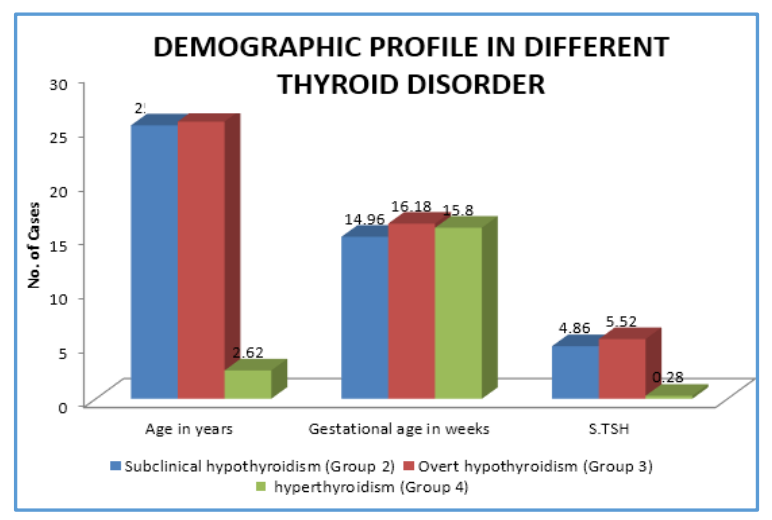

Figure 2 
Maternal complications included preeclampsia (15.8\%), abortions (12.2\%), abruptio placentae (7.14\%), PPH (4.6\%), PPROM (7.14\%) and Anaemia (22.4\%). Among maternal complications, preeclampsia was commonest complication in patients with thyroid dysfunction followed by abortions and placental abruption (as shown in Table 3).

\begin{tabular}{|c|c|c|c|c|c|c|c|}
\hline $\begin{array}{c}\text { Maternal } \\
\text { Complications }\end{array}$ & $\begin{array}{c}\text { Normal } \\
\text { (Group 1) (n= 1072) }\end{array}$ & $\begin{array}{c}\text { Subclinical Hypothyroidism } \\
\text { (Group 2) (n= 142) }\end{array}$ & $\begin{array}{c}\text { Overt Hypothyroidism } \\
\text { (Group 3) (n= 44) }\end{array}$ & $\begin{array}{c}\text { Hyperthyroidism } \\
\text { (Group 4) (n= 10) }\end{array}$ \\
\hline Preeclampsia & $4.4(48)$ & $12.6(18)$ & $<0.001$ & $22.7(10)$ & $<0.001$ & $30(2)$ & $<0.01$ \\
\hline Abortion & $2.24(24)$ & $5.6(8)$ & 0.018 & $11.3(5)$ & $<0.001$ & $20(2)$ & $<0.01$ \\
\hline Abruptio placentae & $1.4(15)$ & $4.2(6)$ & 0.016 & $15.9(7)$ & 0.001 & $10(1)$ & 0.025 \\
\hline PPH & $1.86(20)$ & $3.5(5)$ & 0.19 & $9.1(4)$ & $<0.001$ & 0 & 0 \\
\hline PPROM & $2.24(24)$ & $4.9(7)$ & 0.05 & $13.6(6)$ & $<0.001$ & $10(1)$ & 0.10 \\
\hline
\end{tabular}

Neonatal complications included preterm birth (11.2\%), low birth weight (10.2\%), IUGR (7.14\%), still birth and IUD (6.6\%), NICU admissions (13.7\%) and low APGAR score (13.2\%). Among neonatal complications, preterm birth was commonest complication followed by low birth weight, IUGR and still birth (as shown in Table 4). NICU admissions and low APGAR score (< 7) were common in patients with thyroid dysfunction.

\begin{tabular}{|c|c|c|c|c|c|c|c|}
\hline $\begin{array}{c}\text { Neonatal } \\
\text { Complications }\end{array}$ & $\begin{array}{c}\text { Normal } \\
\text { (Group 1) (n= 1072) }\end{array}$ & \multicolumn{2}{|c|}{$\begin{array}{c}\text { Ubbclinical Hypothyroidism } \\
\text { (Group 2) (n= 142) }\end{array}$} & \multicolumn{2}{c|}{$\begin{array}{c}\text { Overt Hypothyroidism } \\
\text { (Group 3) (n= 44) }\end{array}$} & $\begin{array}{c}\text { Hyperthyroidism } \\
\text { (Group 4) (n= 10) }\end{array}$ \\
\hline Preterm birth & $4.85(52)$ & $10.5(15)$ & 0.03 & $11.4(5)$ & 0.053 & $20(2)$ & 0.028 \\
\hline Low birth weight & $4.3(46)$ & $8.4(12)$ & 0.031 & $15.9(7)$ & $<0.001$ & $10(1)$ & 0.0165 \\
\hline IUGR & $1.3(14)$ & $4.9(7)$ & 0.0019 & $11.4(5)$ & $<0.001$ & $20(2)$ & $<0.01$ \\
\hline IUD + Still birth & $1.5(16)$ & $5.6(5)$ & $<0.001$ & $6.8(3)$ & 0.0078 & $20(2)$ & $<0.001$ \\
\hline NICU admissions & $5.4(58)$ & $14.8(21)$ & 0.04 & $13.6(6)$ & 0.0217 & 0 & 0 \\
\hline Low APGAR score & $6.15(66)$ & $11.2(16)$ & 0.024 & $18.2(8)$ & 0.0016 & $20(2)$ & 0.04 \\
\hline \multicolumn{7}{|r|}{} \\
\hline
\end{tabular}

Percentage of caesarean section was significantly higher in patients with thyroid dysfunction and was more common in overt hypothyroidism group. Anaemia was found to be more common in patients with thyroid dysfunction as compared to normal group.

\section{DISCUSSION}

In India, the prevalence of hypothyroidism in pregnancy is much higher compared to western countries. Prevalence varies widely among various states in India. Various reasons have been proposed for increased prevalence of hypothyroidism in India, as we still face iodine deficiency in many parts of the country. Most common cause of hypothyroidism in pregnancy in India is iodine deficiency. Chronic autoimmune thyroiditis is the commonest cause of hypothyroidism in iodine sufficient areas. Presence of goitrogens in diet, micronutrient deficiency such as selenium and iron deficiency may cause hypothyroidism.

It is now well established that not only overt, but subclinical thyroid dysfunction can also have adverse effects on maternal and foetal outcome. Significant foetomaternal adverse effects were seen in pregnancy complicated by thyroid disorder like abortion, preeclampsia, placental abruption, PPH, PPROM, Preterm birth, IUGR, LBW and IUD emphasising the importance of routine antenatal thyroid screening. Many of these adverse effects could be prevented by early detection and appropriate treatment.

In our study prevalence of thyroid dysfunction was $15.5 \%$. Similar results were shown by studies conducted by Sarala Devi R et al[5] (11.6\%), Rajita S Jani et al[6] (13\%) Ajmani et al[7] (13.25\%) and Sahu MT et al[8] (12.7\%). Results were not consistent with the studies conducted by Rajput et al[9] (26.5\%) and Rao et al[10] (21.1\%).

The prevalence of subclinical hypothyroidism $(\mathrm{SCH})$ in our study was $11.2 \%$. Similar results were shown by studies conducted by Ajmani SN et al[7] (9\%) and Rao et al[10] (14.3\%).
Prevalence was very high in studies conducted by Rajput $R$ et al[9] (21.5\%) and not consistent with our study.

The prevalence of overt hypothyroidism in our study was $3.5 \%$. Similar results were shown by studies conducted by Sarala Devi R et al[5] (2.8\%) and Ajmani et al[7] (3\%). Results were not consistent with the studies conducted by Sahu MT et al[8] (4.58\%), Rao et al[10] (6.2\%).

The prevalence of hyperthyroidism in our study was $0.8 \%$ and all were overt hyperthyroid cases. Similar results were shown by studies conducted by Rao et al[10] $(0.6 \%)$ and Singh Alpana et al[11] $(0.75 \%)$. Results were not consistent with the studies conducted by Ajmani et al[7] $(1.25 \%)$, Sahu MT et al[8] (1.6\%) and Sarala Devi R et al[5] (2.4\%).

In our study, prevalence of thyroid dysfunction was more in primigravida in age group below 25 years and in middle class urban population. A study conducted by Goel M et al showed high prevalence of hypothyroidism in multigravida $(61.5 \%)$ than primigravida (38.5\%). Prevalence was high in age group of 21 - 25 years (48.6\%) than 26 - 30 years' age group (37.5\%), and all the study subjects belonged to either poor or lower middle socio-economic status and mean maternal age was 25.4 years.[12] Study conducted by Singh Alpana et al showed that most of the cases were primigravidae; however, there was no statistically significant association between gravidity and thyroid dysfunction.[11] A study conducted by Nirmala $\mathrm{C}$ et al showed high prevalence of hypothyroidism in primigravidae $(57.7 \%)$ and age group $<30$ years $(71.8 \%)$ and majority of them belonged to middle class status $(57.7 \%)$. [13]

Our study showed that rate of caesarean section was significantly high in pregnancies complicated by thyroid dysfunction as compared to euthyroid women. A study of 
Singh Alpana et al showed high incidence of caesarean section in hypothyroidism (39.28\%).[11] In a study by Sahu MT et al, the incidence of caesarean section was $54.2 \%$. The indications for caesarean section were foetal distress, preeclampsia, IUGR, PPROM, bad obstetric history and previous caesarean section.[8] This indicates that thyroid disorders directly influence the maternal and foetal health.

In our study, thyroid dysfunction was associated with high incidence of maternal complications like abortion, preterm labour, preeclampsia, abruption, PPH, PPROM, anaemia and neonatal complications like preterm birth, low birth weight, IUGR, still birth and IUD.

\section{CONCLUSION}

Maternal hypothyroidism is a disorder with great potential to adversely affect maternal and foetal outcome, so it should be mandatory to screen all the antenatal women in the first trimester by doing S. TSH and FT4, so as to identify at risk pregnancies very early, prompt initiation of treatment, adequate follow-up and most importantly sufficient education of the doctors and the patients regarding these objectives so that not even a single mother will be deprived of it.

Since in our study, we observed high prevalence of foetomaternal adverse outcomes and complications in pregnancies with thyroid dysfunction, therefore we advised thyroid screening of all antenatal women irrespective of gestational age.

\section{REFERENCES}

[1] Klein RZ, Haddow JE, Faix JD, et al. Prevalence of thyroid deficiency in pregnant women. Clin Endocrinol (Oxf) 1991;35(1):41-6.

[2] Mandel SJ. Hypothyroidism and chronic autoimmune thyroiditis in the pregnant state: maternal aspects. Best Pract Res Clin Endocrinol Metab 2004;18(2):21324.

[3] Allan WC, Haddow JE, Palomaki GE, et al. Maternal thyroid deficiency and pregnancy complications: implications for population screening. J Med Screen 2000;7(3):127-30.
[4] Green AS, Abalovich M, Alexander E, et al. Guidelines of the American thyroid association for the diagnosis and management of the thyroid disease during pregnancy and postpartum. Thyroid 2011;21(10):1081-125.

[5] Saraladevi R, Kumari TN, Shreen B, et al. Prevalence of thyroid disorder in pregnancy and pregnancy outcome. IAIM 2016;3(3):1-11.

[6] Jani RS, Munshi DS, Jani SK, et al. Prevalence and fetomaternal outcome of thyroid disorder in pregnancy. Int J Med Sci Public Health 2014;3(8):9447.

[7] Ajmani SN, Aggarwal D, Bhatia P, et al. Prevalence of overt and subclinical thyroid dysfunction among pregnant women and its effect on maternal and fetal outcome. J Obstet Gynaecol India 2014;64(2):105-10.

[8] Sahu MT, Das V, Mittal S, et al. Overt and subclinical thyroid dysfunction among Indian pregnant women and its effect on maternal and fetal outcome. Arch Gynecol Obstet 2010;281(2):215-20.

[9] Rajput R, Goel V, Nanda S, et al. Prevalence of thyroid dysfunction among women during the first trimester of pregnancy at a tertiary care hospital in Haryana. Indian J Endocrinol Metab 2015;19(3):416-9.

[10] Rao S, Patibandla A. A study to find out the prevalence of hypothyroidism among pregnant women visiting ESI hospital, Sanathnagar Hyderabad. Gynecol Obstet (Sunnyvale) 2016;6(3):363.

[11] Singh A, Reddy MJ. Prevalence of thyroid dysfunction in pregnancy and its implications. Int J Med Sci Public Health 2015;4:1247-50.

[12] Goel M, Sharma A, Agarwal A, et al. Prevalence of subclinical hypothyroidism in North Indian pregnant women. Int J Reprod Contracept Obstet Gynecol 2015:4(4):1034-7.

[13] Nirmala C, Jayakumari C, Rajasekharan C, et al. Maternal outcome of hypothyroidism in pregnancy-a south Indian perspect. American Journal Of Clinical Medicine Research 2014;2(2):47-50. 